\title{
Phenomenology and Severity of Symptoms in OCD Patients After COVID 19: A Cohort Study
}

\author{
Usha Nandhini ${ }^{1}$, S Vaishali ${ }^{1}$, Ahalya Vedachalam ${ }^{2}$, S Sudhakar ${ }^{2}$, PP Kannan ${ }^{3}$
}

\section{ABSTRACT}

Background: COVID 19 pandemic and the associated restrictions can have significant impact on patients with pre-existing mental disorders. Fear of getting infected and excessive focus on contamination can worsen in patients with OCD.

Methodology: Thirty patients with OCD attending Chengalpattu Medical College Hospital were evaluated for OCD symptom severity using Y-BOCS severity scores in June \& July 2020 and that was compared with their scores five months prior (pre covid)

Results: Majority of the study population (53\%) had no changes in symptom severity after the onset of COVID19 pandemic. Twenty seven percent (27\%) had a decrease in symptom severity while only $20 \%$ had increase in severity.

Conclusion: Our study results indicate that there were no significant changes in OCD symptom severity after the onset of COVID 19 pandemic.

Keywords: OCD, COVID 19, Severity

Running Title: Changes in OCD in COVID pandemic

Address for Correspondence: Dr. Sudhakar. S, Assistant Professor, Department of Psychiatry, Government Chengalpattu Medical College, Chengalpattu, Tamilnadu, India. E-mail: sudhakarpsychiatrist@yahoo.com

How to Cite this Article: Nandhini U, Vaishali S, Vedachalam A, Sudhakar S, Kannan PP. Phenomenology and severity of symptoms in OCD patients after COVID 19: A cohort study: A case report. Indian Journal of Mental Health and Neurosciences. 2020;4(1): pp 18-22

\section{INTRODUCTION}

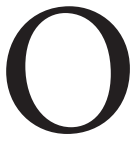
bsessive-compulsive disorder (OCD) is a neuropsychiatric disorder with prevalence of $1-3 \%$ in general population. ${ }^{1}$ OCD is characterized by recurrent obsessions, such as persistent thoughts, impulses or mental images, that promote anxiety, and uncontrolled compulsions such as repetitive behaviours or mental acts that are performed in response to the obsessions with the intent of reducing anxiety. Of the multiple symptom domains, obsessions of contamination and compulsive hand washing are amongst the commonest. These domains respond well to pharmacotherapy and psychotherapy, it tends to relapse in case of stress due to external or environmental cues. ${ }^{2}$

Adam Abba et al, ${ }^{3}$ reported that the prevalence of OCD symptoms increased during the early phase of the COVID-19 pandemic, at a rate significantly higher than pre-pandemic rates in the general population. Also, other studies have suggested that there could be significant worsening of (OCD) in the context of the current COVID-19 pandemic. ${ }^{4,5,6,7}$ One study reported that psychoeducation of the patients and families,facilitating tele-consults and psychotherapy, enhancing medication compliance and social worker input potentially reduce the worsening of symptoms in this population. ${ }^{5}$

Hence the aim of this study was to understand the impact of Covid-19 on the mental health of patients with OCD in an Indian setting and find out if there is a need to modify or intensify their treatment.

\section{METHODOLOGY}

The study was conducted in the psychiatry department of Chengalpattu medical college and hospital in Tamilnadu. Thirty patients with OCD who were already

${ }^{1}$ Junior Resident, Department of Psychiatry, Chengalpattu medical college; ${ }^{2}$ Assistant Professor, Department of Psychiatry, Chengalpattu Medical College, ${ }^{3}$ Professor of Psychiatry, Department of Psychiatry, Chengalpattu Medical College. 
a part of a previous study were reassessed for severity of OCD symptoms in June and July 2020. These scores were compared with that from the earlier assessment of severity done in January \& February 2020. The protocol was approved by the institute ethics committee and patients provided informed consent to be part of this study.

\section{Measures}

Socio demographic and clinical profile was obtained using a semi structured proforma. The Y-BOCS-SC was used to identify the content of the obsessions and compulsions8 and the Y-BOCS Severity Score, a 10item instrument developed by Goodman et al was used to evaluate symptom severity and treatment response. 8 The knowledge of patients about Covid-19 was assessed using semi-structured interview. This consisted of five questions regarding the mode of spread, symptoms of the illness, course of illness, treatment available and preventive measures

SPSS software was used for statistical analysis. Descriptive statistics of socio demographic and clinical profile was used. Paired $\mathrm{t}$ - test analysis was performed for comparison of mean scores of YBOCS before and during COVID 19.

\section{RESULTS:}

Socio demographic characteristics

In our sample $60 \%$ [ $n=18]$ were male and $60 \%$ [ $n$ $=18]$ were from rural background. $50 \%$ [ $n=15]$ had primary level of education. $60 \%$ [ $n=18]$ were employed and $73 \%[n=22]$ were married. (Table 1)

Table 1: Demographic details, $(n=30)$

\begin{tabular}{|c|c|c|c|c|}
\hline S No & \multicolumn{2}{|c|}{ Variable } & Frequency & Percentage \\
\hline \multirow[t]{4}{*}{1} & \multirow[t]{4}{*}{ Age } & $20-30$ & 9 & 30 \\
\hline & & $31-40$ & 9 & 30 \\
\hline & & $41-50$ & 9 & 30 \\
\hline & & $>50$ & 3 & 10 \\
\hline \multirow[t]{2}{*}{2} & \multirow[t]{2}{*}{ Gender } & Male & 18 & 60 \\
\hline & & Female & 12 & 40 \\
\hline \multirow[t]{3}{*}{3} & \multirow[t]{3}{*}{ Locality } & Rural & 14 & 47 \\
\hline & & Semi urban & 8 & 27 \\
\hline & & Urban & 8 & 27 \\
\hline \multirow[t]{2}{*}{4} & \multirow[t]{2}{*}{ SES } & Lower & 16 & 53 \\
\hline & & Middle & 14 & 47 \\
\hline \multirow[t]{4}{*}{5} & \multirow[t]{4}{*}{ Education } & Illiterate & 1 & 3 \\
\hline & & Primary & 15 & 50 \\
\hline & & Secondary & 6 & 20 \\
\hline & & College & 8 & 27 \\
\hline \multirow[t]{4}{*}{6} & \multirow[t]{4}{*}{ Employment } & Professional & 1 & 3 \\
\hline & & Skilled & 5 & 17 \\
\hline & & Semi skilled & 12 & 40 \\
\hline & & Unemployed & 12 & 40 \\
\hline \multirow[t]{3}{*}{7} & \multirow[t]{3}{*}{ Marital status } & Married & 22 & 73 \\
\hline & & Unmarried & 7 & 23 \\
\hline & & Divorced & 1 & 3 \\
\hline
\end{tabular}




\section{Clinical Characteristics}

Many had duration of illness greater than 5 years, $66 \%$ [ $n=20$ ]. About $10 \%$ [ $n=3$ ] were drug naïve and $50 \%$ [ $n=15$ ] were on regular treatment.23\% [ $n=7$ ] had a past history of suicide attempt. $20 \%$ [ $n=6$ ] had a family history of psychiatric illness and 43\% [ $n=13]$ had alcohol use. (Table 2)

Table 2: Clinical characteristics of the sample

\begin{tabular}{|c|c|c|c|c|}
\hline S No. & \multicolumn{2}{|c|}{ Variable } & Frequency & Percentage \\
\hline \multirow[t]{3}{*}{1} & \multirow[t]{3}{*}{ Duration of illness } & $<5$ years & 10 & 33 \\
\hline & & 5-10 years & 16 & 53 \\
\hline & & $>10$ years & 4 & 13 \\
\hline \multirow[t]{3}{*}{2} & \multirow[t]{3}{*}{ Treatment history } & Regular & 15 & 50 \\
\hline & & Irregular & 12 & 40 \\
\hline & & Drug naive & 3 & 10 \\
\hline \multirow[t]{3}{*}{3} & \multirow[t]{3}{*}{ Past history } & Seizure disorder & 2 & 7 \\
\hline & & Suicide attempt & 7 & 23 \\
\hline & & Nil & 21 & 70 \\
\hline \multirow[t]{2}{*}{4} & \multirow[t]{2}{*}{ Family history } & No & 24 & 80 \\
\hline & & Yes & 6 & 20 \\
\hline \multirow[t]{4}{*}{5} & \multirow[t]{4}{*}{ Substance use } & Alcohol & 13 & 43 \\
\hline & & Alcohol and Tobacco & 1 & 3 \\
\hline & & Tobacco & 1 & 3 \\
\hline & & Nil & 15 & 50 \\
\hline
\end{tabular}

Profile of OCD in the sample

Obsesions on themes of contamination, aggression was most common. Cleaning and checking compulsions were the most frequent. The different types of obsessions and compulsions seen and their frequency of occurrence in this study population is noted.(Table 3 )

Table 3: Frequency of obsessions and compulsions by domain

\begin{tabular}{|l|l|c|c|}
\hline S No. & Obsessions & Frequency & Percent \\
\hline 1 & Aggressive & 9 & $23 \%$ \\
\hline 2 & Contamination & 9 & $23 \%$ \\
\hline 3 & Somatic & 4 & $10 \%$ \\
\hline 4 & Religious & 3 & $8 \%$ \\
\hline 5 & Sexual & 8 & $21 \%$ \\
\hline 6 & Miscellaneous & 2 & $5 \%$ \\
\hline 7 & Symmetry & 2 & $5 \%$ \\
\hline 8 & Nil & 2 & $5 \%$ \\
\hline S No. & Compulsions & Frequency & Percent \\
\hline 1 & Cleaning & 17 & $36 \%$ \\
\hline 2 & Checking & 13 & $28 \%$ \\
\hline 3 & Miscellaneous & 5 & $11 \%$ \\
\hline 4 & Repeating rituals & 4 & $9 \%$ \\
\hline 5 & No compulsions & 8 & $17 \%$ \\
\hline
\end{tabular}




\section{Changes in severity of symptoms after COVID 19}

We found that about $20 \%$ [ $n=6$ ] of the patients had increase in the severity of symptoms following COVID 19 while $27 \%[n=8]$ of the patients had decrease in the severity of symptoms and $53 \%[n=16]$ of the patients had no changes in the severity of symptoms following COVID 19.Paired samples t-test showed there was no significant difference ( $p$ value- 0.202 ) in the Y BOCS score before (16.04) and after pandemic (15.03).(Table 4)

Table 4: Change in severity of symptoms after COVID 19

\begin{tabular}{|l|c|c|}
\hline \multicolumn{1}{|c|}{ Change in severity } & Frequency & Percentage \\
\hline Increased & 6 & $20 \%$ \\
\hline Decreased & 8 & $27 \%$ \\
\hline No changes & 16 & $53 \%$ \\
\hline Change in YBOCS & Mean Score & p value \\
\hline Pre Pandemic & 16.04 & \multirow{2}{*}{0.202} \\
\hline Post Pandemic & 15.03 & \\
\hline
\end{tabular}

\section{DISCUSSION}

The spread of fear, anxiety and even panic due to the COVID-19 pandemic can lead to a worsening of preexisting psychiatric disorders (Yao et al., 2020). ${ }^{9}$ There are few studies in India regarding the changes in OCD symptoms following COVID 19.

In our sample of 30 patients only $20 \%$ of the patients had increase in the severity of symptoms following COVID 19. As a whole group, there was no significant differences in severity of symptoms before and after the onset of COVID 19. This is different to the findings of another studies by Davide et al, of 30 patients, where they found that there was overall worsening of symptoms. ${ }^{10}$ That study included only patients with contamination symptoms whereas, in this sample patients with all subtypes were included. The mean YBOCS score before the COVID 19 was 15.97 which is like our sample score 16. 04. The mean YBOCS score during pandemic was 20. 6 in their sample which is higher than in our sample which was 15.03 .

In a cross-sectional study conducted by Benatti et al, $36 \%$ of the patients had clinical worsening of symptoms which is little higher than our sample were only $20 \%$ had worsening of symptoms. $39 \%$ were employed in their study which is contradictory to our sample were $60 \%$ were employed. Most common obsession was aggressive type and compulsions were cleaning type which is similar to our sample. ${ }^{11}$

There could be a few reasons why there was no significant worsening in the study sample. The clients with OCD in this study were continuing their treatment for a longer duration (majority with an illness duration of more than five years). They might represent a group with better understanding of their condition, significant clinical improvement, resilience and better ability to deal with the challenges posed by the pandemic. Most of the patients were on regular follow up and treatment even during the lockdown and for those who couldn't reach the hospital, tele-therapy was started and based on the symptoms patients were advised to get drugs from nearby hospitals.

\section{LIMITATIONS}

Our study had a small sample size from a tertiary care hospital and results cannot be generalized. There is high risk of selection bias as those who follow up regularly might be a group with better prognosis. Half of the patients in our sample had mild to moderate severity, so the impact on those with severe illness could be underestimated. 


\section{CONCLUSION AND FUTURE DIRECTIONS}

The effects of pandemic on the mental health in OCD patients might be variable. It is necessary that the patients to be in regular follow up and treatment during pandemic.Follow up study with large sample size to be included. That will allow comparison between those with predomination contamination obsessions and others. It will be useful to study if the understanding of COVID19 reduces the risk of worsening.

\section{Acknowledgement: None}

Source of Funding: This research has not received specific financialgrant from any funding agency in the public, commercial or not-for-profit sectors

Conflict of Interest: The authors have declared no conflict of interest with respect to the research, authorship,and/or publication of this article

\section{REFERENCES}

1 Fontenelle LF, Mendlowicz MV, Versiani M. The descriptive epidemiology of obsessive-compulsive disorder. Progress in Neuro-psychopharmacology \& Biological Psychiatry. 2006; 30(3):327-337

2 Cordeiro T, Sharma MP,Thennarasu K, et al. Symptom dimensions in obsessive-compulsive disorder and obsessive beliefs. Indian Journal of Psychological Medicine. 2015;37(4):403-408

3 Abba-Aji A, Hrabok M, Shalaby R. COVID-19 pandemic and mental health: prevalence and correlates of new- onset obsessive-compulsive symptoms in a Canadian province. International Journal of Environmental Research and Public Health. 2020;17(19):6986

4 Santos CF. Reflections about the impact of the SARS-COV-2/COVID-19 pandemic on mental health. Brazilian Journal of Psychiatry. 2020;42(3):329

5 Banerjee DD. The other side of COVID-19: impact on obsessive compulsive disorder (OCD) and hoarding. Psychiatry Research. 2020;288:112966

6 ShanmugamH, Juhari JA, Nair P, et al. Impacts of COVID-19 pandemic on mental health in Malaysia: a single thread of hope. Malaysian Journal of Psychiatry. 2020;29(1):78-84

7 FinebergNA, Van Ameringen M, Drummond L, et al. How to manage obsessive-compulsive disorder (OCD) under COVID-19: A clinician's guide from the International College of Obsessive-Compulsive Spectrum Disorders (ICOCS) and the Obsessive-Compulsive Research Network (OCRN) of the European College of Neuropsychopharmacology. Comprehensive Psychiatry.100:152174

8 Goodman WK, Price LH, Rasmussen SA, et al. The Yale-Brown obsessive-compulsive scale: I. development, use, and reliability. Archivesof General Psychiatry. 1989;46(11):1006-1011

9 Yao H, Chen JH, Xu YF. Patients with mental health disorders in the COVID-19 epidemic. Lancet Psychiatry. 2020;7(4):e21

10 Davide P, Andrea P, Martina O. The impact of the COVID-19 pandemic on patients with OCD: effects of contamination symptoms and remission state before the quarantine in a preliminary naturalistic study. 2020;291:113213

11 Benatti B, Albert U, Maina G, et al.What Happened to patients with obsessive compulsive disorder during the COVID-19 pandemic? a multicentre report from tertiary clinics in northern Italy. Frontiers in Psychiatry. 2020;11:720 